\title{
The Geographic Distributions of Cicada Killers (Sphecius; Hymenoptera, Crabronidae) in the Americas
}

\author{
Joseph R. Coelho*,1, Charles W. Holliday ${ }^{2}$ and Jon M. Hastings ${ }^{3}$ \\ ${ }^{1}$ Institute for Franciscan Environmental Studies, Biology Program, Quincy University, Quincy, IL 62301, USA \\ ${ }^{2}$ Department of Biology, Lafayette College, Easton, PA 18042, USA \\ ${ }^{3}$ Department of Biological Sciences, Northern Kentucky University, Highland Heights, KY 41099, USA
}

\begin{abstract}
The distributions of American cicada killers (Sphecius) were examined via solicited and museum specimens. $S$. hogardii occurs in southern Florida and several Caribbean islands. S. speciosus occurs throughout the east coast, southeast, and Midwestern states at high densities, and its range extends much farther west than expected, but not west of the continental divide. S. speciosus appears to be excluded from high altitudes. S. grandis and S. convallis occur at higher altitudes and are largely sympatric throughout the west, but are most common in lower riparian regions. Sphecius grandis is found at significantly higher altitudes than $S$. convallis. Both are sympatric with S. speciosus on both sides of the Rio Grande. The northern boundaries of Sphecius extend to $48.2^{\circ} \mathrm{N}$ latitude, and are associated with well known faunal zones. The continental divide may have served as a geographic barrier, playing a role in the evolution of American Sphecius by allopatric speciation.
\end{abstract}

Keywords: Crabronidae, Sphecius, distribution, ecology, habitat.

\section{INTRODUCTION}

The geographic range of an organism is a fundamental part of its ecology and may reveal a great deal of its biology. Distribution data are essential for conservation efforts [1], yet accurate and complete distribution maps of most invertebrates are unavailable. Many existing distribution maps are based on data from a small number of specimens, and may under-represent the full geographic range of the animal. For example, Irwin and Coelho [2], using GPS, showed that the surface area covered by Brood III periodical cicadas in Illinois was approximately twice that indicated in an earlier study based solely on museum specimens [3]. Determination of the ranges of insects may be so daunting that a recent strategy involves using computer algorithms to generate theoretical range maps based on the limited data available for a species $[4,5]$.

Cicada killers (Sphecius spp.) are large wasps that have long been featured in popular literature [6-10]. Females forage on annual cicadas and carry the paralyzed prey back to their burrows in flight $[11,12]$. Unfortunately, their large size, the intense flight activity of territorial males in dense aggregations, and aesthetic damage to turf and gardens caused by burrowing females [13-15] may cause them to be perceived as pests. A thorough bibliography [16] lists 92 references involving cicada killers. In spite of their popularity as study animals and their notoriety with the public, the distributions of cicada killer species are poorly defined. Approximate geographical boundaries or state-by-state distribution of each North American species are available [17-

*Address correspondence to this author at the Institute for Franciscan Environmental Studies, Biology Program, Quincy University, Quincy, IL 62301, USA; Tel: 217-228-5432, ext. 3268; E-mail: coelhjo@quincy.edu
19]. Improved range descriptions are included as part of a taxonomic key [20], based upon preliminary data included in this study. The eastern cicada killer (Sphecius speciosus Drury) is the best known of the five New World species. A brief field guide [21] has provided the only range map of the eastern cicada killer, indicating its presence in the eastern United States, primarily east of the line of aridity $\left(100^{\circ} \mathrm{W}\right.$ longitude) and south of the Great Lakes. Correspondence with investigators and visitors to our web sites indicated that eastern cicada killers are found well outside these limits (e.g., Big Bend National Park, Brewster Co., TX). The 1987 edition of the same field guide [22] indicated that the range of the eastern cicada killer extended throughout the 48 contiguous United States - a likely overestimate of their geographic limits. Clearly, estimated boundaries of the eastern cicada killer distribution are murky.

We had correspondence regarding cicada killers from around the country for several years as a result of our cicada killer web pages. Recognizing an opportunity to enlist these individuals as data collectors in a citizen science initiative (see [23]), we solicited photographs and specimens. In addition to the eastern species, three other species of Sphecius occur in North America: the western cicada killer (S. grandis Say), the Pacific cicada killer (S. convallis Patton), and the Caribbean cicada killer ( $S$. hogardii Latreille). Distributions of these species are even less well known than that of $S$. speciosus. Identification may be part of the problem, as $S$. grandis and $S$. convallis are morphologically similar. A published key [24] reversed them, and only recently was that error corrected [20] and definitive characters provided to distinguish them.

The goal of this study was to determine the distributions of the four species of Sphecius in North America north of Mexico and, in a less comprehensive way, in Mexico and 
Central America, as well as the distribution of S. spectabilis in South America. Having gathered these data, we were also able to gain insight into aspects of the biology of these animals, including habitat, prey species and evolutionary history.

\section{MATERIALS AND METHODS}

Specimens from museums, personal collections, and those provided by the public were used for this study as well as records from the literature and photographic evidence provided by collaborators. Reports documented with clear, diagnostic photographs were accepted from individuals in response to solicitations posted on our web pages $[25,26]$ and during the period June 2004 through October 2008. Some individuals were only able to email us digital photographs of specimens, which were adequate for identification, but most sent specimens in a postage-paid mailing kit. The authors were responsible for all identifications. Institutions which loaned us specimens, allowed us access to their collections or sent label data are listed in Appendix I of [20]. The common names of cicada killers used in this paper are those approved by the Entomological Society of America.

The latitude and longitude of the collection locations provided for each specimen were determined using one of three geographic resources: MapsOnUs [27] and USGS GNIS [28] or Google Earth [29]. For specimens with only county data, we used the coordinates of the county seat. For collection records indicating a large area, such as a state or national park, coordinates at the approximate center of the area were used. For specimens collected by ourselves, coordinates were taken directly by a handheld GPS receiver or determined using Google Earth software. For records in which the location given was reasonably precise, such as a street address or city, altitude was also recorded. At the conclusion of the data collection period, all geocoordinates and altitudes were checked for accuracy with Google Earth.

An electronic spreadsheet of the data was constructed listing record number, species, date of collection, sex, longitude, latitude, elevation state, county, address (when available), collector and museum information, and comments. The spreadsheet was loaded into ArcView GIS ${ }^{\mathrm{TM}}$ ver. 3.1 and coordinates were superimposed on maps. We chose not to construct distribution boundary lines, as they are generally arbitrary, and may lead the reader to false conclusions, e.g., that a species is found everywhere within the boundary, and nowhere outside of it.

Responses to our solicitations for specimens from Mexico and South America were poor. Hence we elected to focus our analysis on the region of high data saturationNorth America north of Mexico. This region is also traditionally covered by field guides and taxonomic treatments (e.g. $[17,30,31])$. We also included the Caribbean region to describe the range of $S$. hogardii. Because of the paucity of records, species ranges south of the U.S.A.-Mexico border are documented but discussed only briefly.

\section{RESULTS}

Institutional collections provided 4017 specimens representing 2876 locations. An additional 3889 wasps from 1133 locations were collected by the authors or provided by individuals in response to solicitations posted on our web pages. Combined, we recorded $>4000$ locations and over 8000 specimens (Table 1). Males were more commonly collected than females in all species except $S$. speciosus. The majority of records was obtained for $S$. speciosus, followed by grandis, convallis and hogardii. S. hogardii and S. spectabilis were represented solely by museum specimens, as none submitted by collaborators. Based upon the specimens submitted by our public collaborators, the introduced European hornet (Vespa crabro L.) was most frequently confused by them with cicada killers. Other species occasionally misidentified as cicada killers included great golden digger wasp (Sphex ichneumoneus L.), various horntails (Siricidae), and yellowjacket queens (Vespula spp.).

At least one species of Sphecius occurs in each of the lower 48 U.S. states, except Maine and Vermont (Fig. 1). Only one record occurs in Wyoming, with two each in North Dakota and New Hampshire, and three in Montana (all $S$. speciosus). A few records of $S$. speciosus occur from just north of Lake Erie in southern Ontario, Canada, but these, at $43.7^{\circ} \mathrm{N}$, are not the northernmost. S. speciosus is recorded from $44.2^{\circ} \mathrm{N}$ just east of these specimens in upstate $\mathrm{New}$ York, and at $48.2^{\circ} \mathrm{N}$ in North Dakota.

The density of records along the northeast coast from Massachusetts to Maryland was high. This pattern may reflect human population density and historical collecting effort more than the density of the eastern cicada killer. A similar pattern appears around Dallas, Texas. We created a map of counties to remove some of this effect (Fig. 2). For Connecticut, Delaware, New Jersey and Rhode Island all counties were represented (by $S$. speciosus).

Fig. (1) shows that the eastern cicada killer (S. speciosus) occurs throughout the east coast, southeast, and midwestern states at high densities, but records become rare near the northern and western edges of its distribution. Its range extends west of the line of aridity $\left(100^{\circ} \mathrm{W}\right.$ longitude), but not

Table 1. Sample Sizes and Altitudes of Cicada Killers from North America North of Mexico and the Caribbean

\begin{tabular}{|c|c|c|c|c|}
\hline Species & Locations & Males & Females & Mean Altitude (m)* \\
\hline \hline S. speciosus & 3018 & 3004 & 3285 & $219 \pm 4.7(2791)$ \\
\hline S. grandis & 607 & 735 & 361 & $755 \pm 23.3(553)$ \\
\hline S. convallis & 343 & 331 & 190 & $582 \pm 30.9(332)$ \\
\hline S. hogardii & 40 & 22 & 22 & $18 \pm 5.0(35)$ \\
\hline Total & 4009 & 4290 & 3858 & $0-0166$ \\
\hline
\end{tabular}

*Mean altitudes for all possible pairwise comparisons of species are significantly different $(\mathrm{P}<0.0001, \mathrm{t}$ test with Bonferroni correction) 


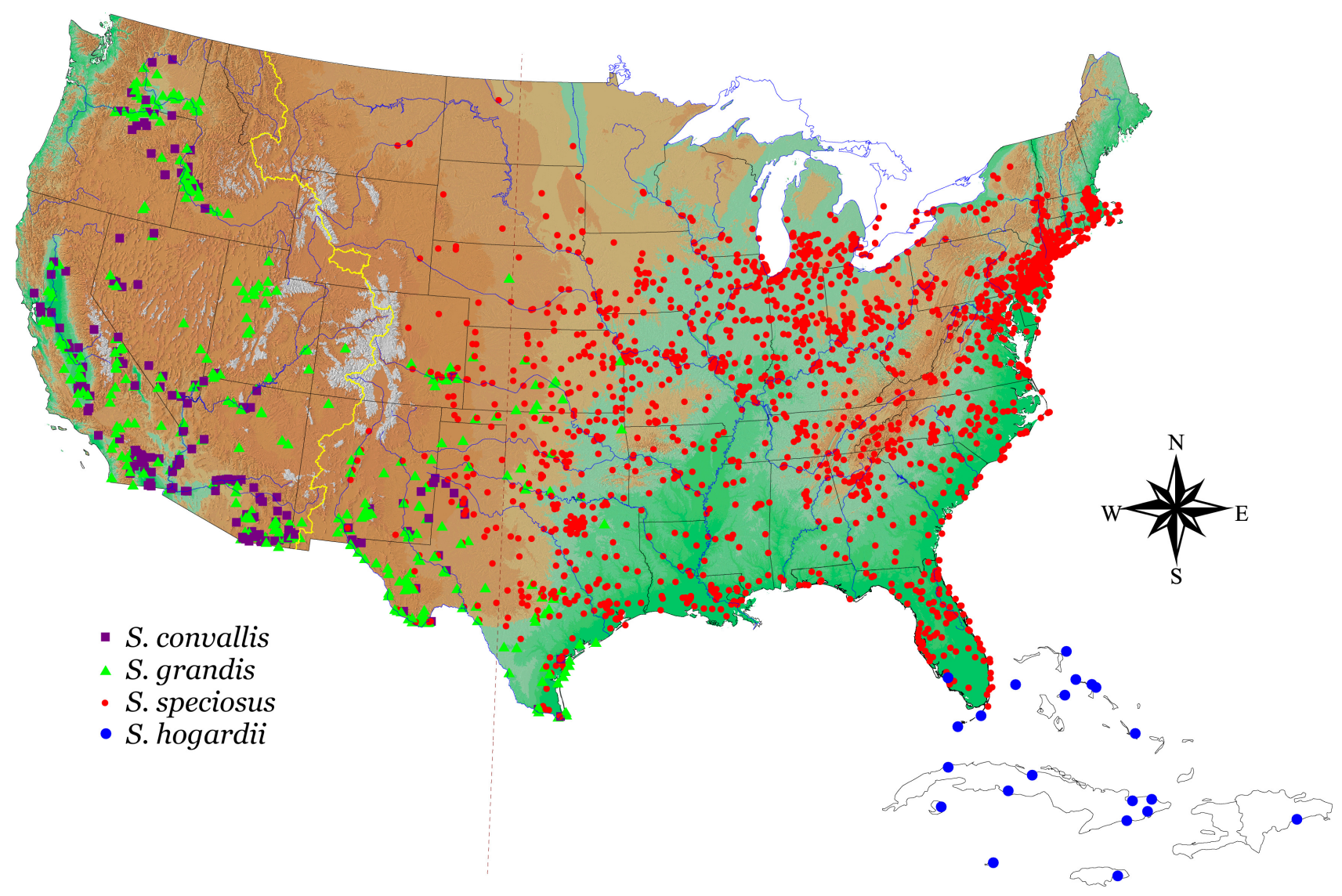

Fig. (1). Locations recorded for cicada killers (Sphecius) plotted. Purple square, S. convallis; green triangle, S. grandis; blue circle, S. hogardii; red circle, S. speciosus; dashed line, $100^{\circ} \mathrm{W}$ longitude (line of aridity); yellow line, continental divide; blue lines, waterways. Relief map indicates altitude by color: dark green, lowest; brown, intermediate, white, highest (except Caribbean islands, where no relief is shown).

west of the continental divide: it is found throughout Texas, Oklahoma, Kansas, Nebraska and South Dakota, as well as eastern portions of Colorado, Wyoming, and Montana.

Sphecius is absent from the higher elevations of the larger mountain ranges: Rockies, Sierras, and Cascades. Indeed, the highest altitudes recorded were in the southwestNew Mexico, Arizona and California. S. speciosus appears to be absent from the northern Appalachian Mountains and other high altitude regions. Interspecific differences in altitude were also observed, as $S$. grandis occurred at the highest mean elevation, followed by $S$. convallis, $S$. speciosus and $S$. hogardii (Table 1). Altitudinal differences were significant between all species pairs.

The western and Pacific cicada killers (S. grandis and $S$. convallis) are largely sympatric throughout the western states (except Utah, where only S. grandis occurs), but are most common in relatively low-altitude and riparian regions, such as the Snake River Valley and California's Great Central Valley. S. convallis and $S$. grandis also have similar northern limits, 47.9 and $47.4^{\circ} \mathrm{N}$, respectively, in northern Washington. Interestingly, both are sympatric with $S$. speciosus in several west Texas counties.

The Caribbean cicada killer (S. hogardii) occurs in Cuba, the Bahamas, the Dominican Republic, southern Florida (including the Keys), Grand Cayman and Jamaica. The northernmost record for $S$. hogardii was $27.3^{\circ} \mathrm{N}$ in Florida. This species has not been recorded in Puerto Rico (N. Franz, personal communication).

To examine the effect of potential sampling bias of individual records, we plotted the U.S. counties where $S$. speciosus was recorded Fig. (2). Eastern cicada killers appear to be concentrated around the east coast. In fact, Sphecius speciosus was recorded from all counties in the eastern states of Delaware, Connecticut, New Jersey, and Rhode Island. High densities are also observed in Florida and an arc running from the upper Midwest southwest to Texas.

S. speciosus was recorded from Mexico (Chihuahua, Coahuila, Nuevo Leon and Tamaulipas), Guatemala (Alta Verapaz), Honduras (Islas de Bahia) and Ecuador (Guayas) (Fig. 3). Sphecius grandis was found in Mexico (Baja California Norte, Baja California Sur, Coahuila, Nuevo Leon, Tamaulipas and Yucatán), Costa Rica (Guanacaste), Honduras (Morazon) and Nicaragua (Granada). Sphecius convallis was found only in Mexico (Baja California Norte, Baja California Sur, Chihuahua, Coahuila, Jalisco, Morelos, Nuevo Leon, Queretaro, San Luis Potosí, Sinaloa, Sonora, Tamaulipas and Yucatán). Sphecius spectabilis (Taschenberg) is probably found throughout much of South 


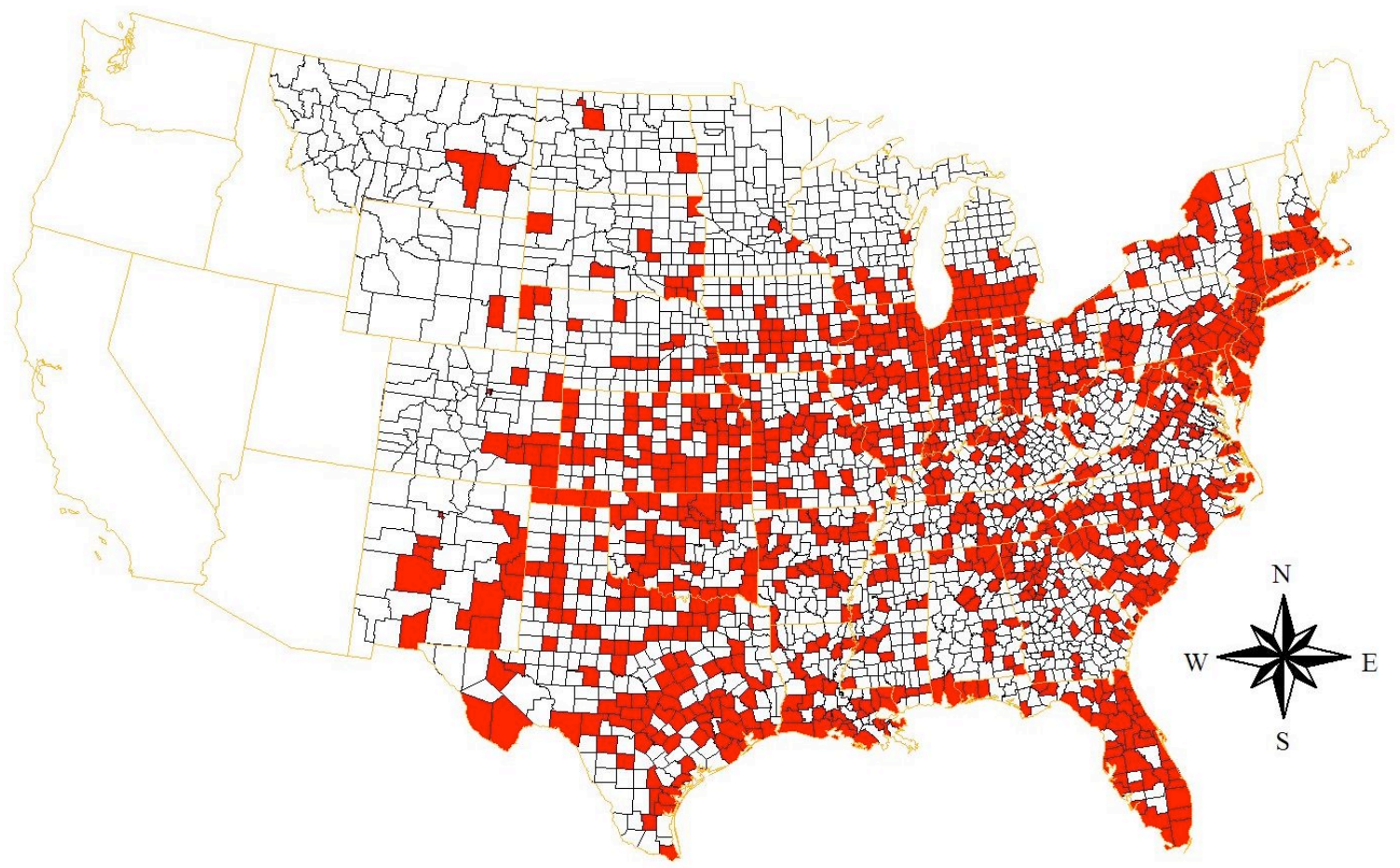

Fig. (2). U.S. counties in which Sphecius speciosus was recorded.

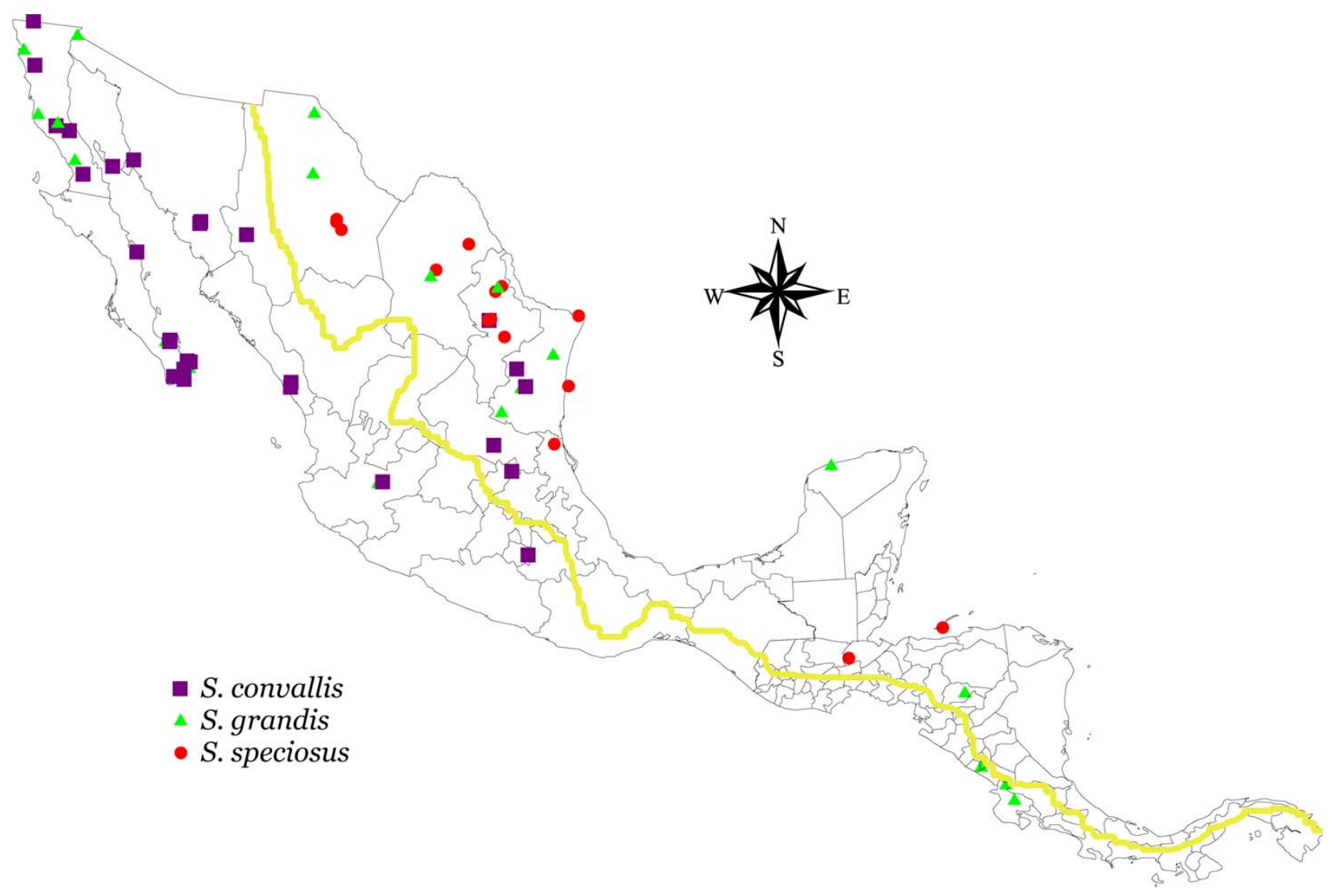

Fig. (3). Cicada killers in Mexico and Central America. Symbols same as Fig. (1); yellow line, continental divide.

America, though records were scattered and we saw none north of $10.1^{\circ} \mathrm{N}$, nor south of $33.5^{\circ} \mathrm{S}$ (Fig. 4). It was recorded from Argentina, Bolivia, Brazil, Chile, Columbia, French
Guiana, Peru, Surinam and Venezuela at elevations ranging from $35 \mathrm{~m}$ (Brazil) to $2844 \mathrm{~m}$ (Chile). S. spectabilis occurs on both sides of the South American continental divide. 

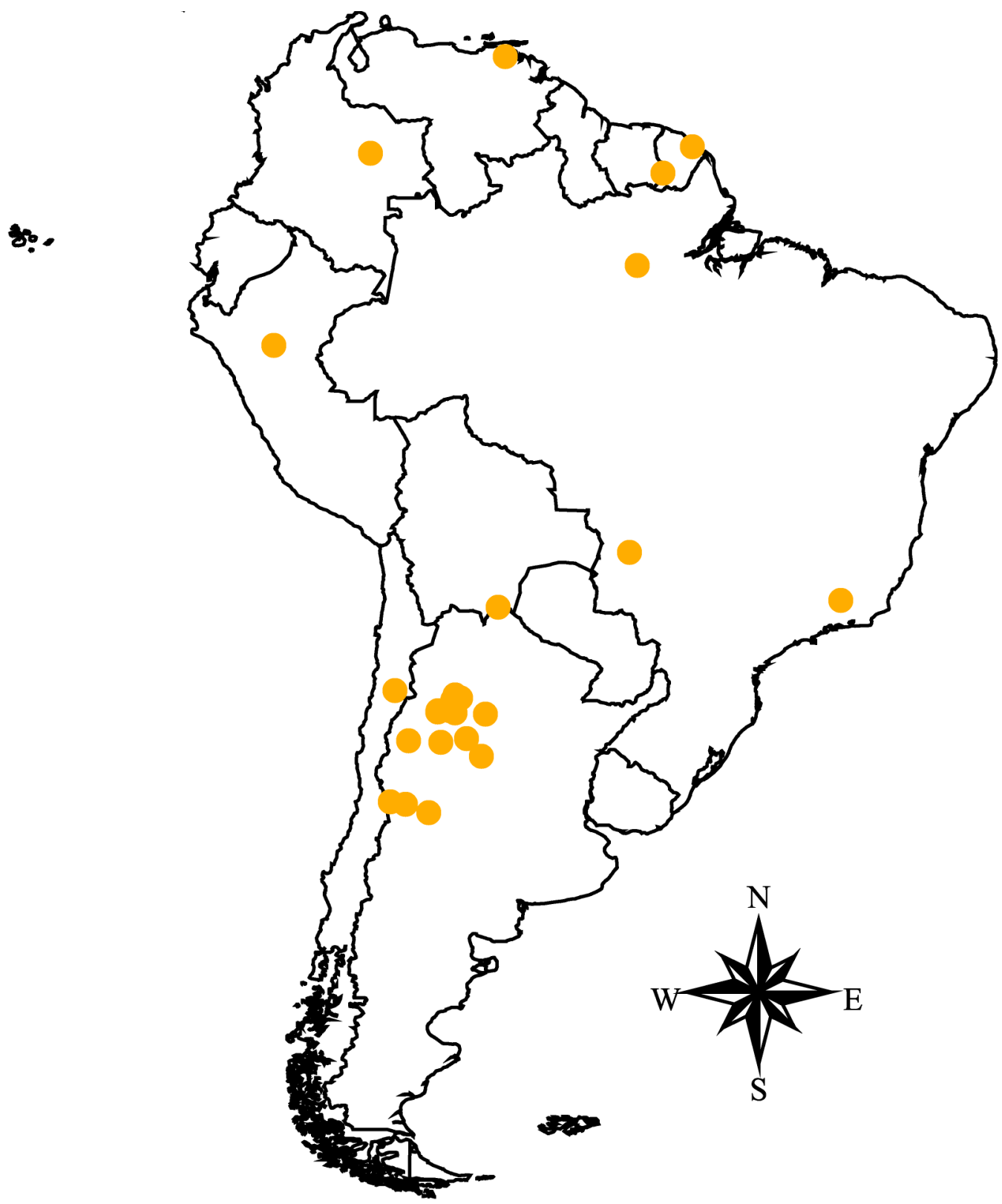

Fig. (4). Records of Sphecius spectabilis in South America.

\section{DISCUSSION}

Sphecius speciosus was first described as being common in the eastern U.S., Texas, and Mexico [19]. Ebeling [18] is more specific, indicating it occurs east of the Rocky Mountains and south into Mexico, and Krombein [17] concurs, while limiting it to the upper and lower Austral Zones. The specification of faunal zones does a relatively good job of describing the range, such as its absence from higher elevations in the Appalachians and northern limit.

Fox [19] describes the range of $S$. convallis as Kansas, Texas, and California into Baja California. Ebeling's [18] description is the same, except for the curious omission of Texas. Krombein [17] again provides more specifics but not a state-by-state list: U.S. west of the 100th meridian and Baja California. However, we did not find S. convallis in several of the states that would be included in this convenient description (e.g. Montana, Wyoming, Colorado), and there is only one county in Utah represented (Washington). We also obtained many records from Mexico outside of Baja California.

S. grandis was first reported from Tennessee, Missouri, Arkansas, Texas, New Mexico, Utah, Nevada, Washington [19]. Ebeling [18] simplifies this list to include Tennessee, Missouri, Arkansas and throughout the West. Krombein [17] repeats Fox's [19] list, and adds Kansas, California and south to Central America. Curiously, we did not see any records 
from Tennessee, Missouri or Arkansas for this species. However, we recorded specimens from Oklahoma, Colorado, New Mexico, Arizona, Idaho, Oregon and Nebraska (one specimen).

Fox [19] mentions $S$. hogardii from Key West in Florida and the Bahamas. Ebeling [18] expands this range to the southern tip of Florida and the West Indies. Krombein [17] concurs with Ebeling [18], but suggests the cicada killer in the Bahamas is a unique subspecies, $S . h$. bahamas. We confirm the distribution as described, and are able to list the islands upon which the wasp has so far been recorded: Grand Cayman, Cuba, Hispaniola (Dominican Republic) and Jamaica. The Bahama Islands are specifically represented by Abaco, Eleuthera, Long, New Providence, and North Bimini.

Sphecius speciosus has a broad range, and part of this success is likely attributable to its synanthropic nature. It has an affinity for human-modified environments, nesting in lawns, flower beds, and other such habitats surrounding human domiciles, in the vast majority of the records sent us by individuals and in most cases observed ourselves. In fact, there were few cases in which $S$. speciosus was found in a natural, undisturbed habitat. Big Bend National Park (Brewster Co., Texas) may be such a case, and perhaps the sand dunes of Kill Devil Hills (Dare Co., North Carolina [32]. The largest aggregation of $S$. speciosus known was recorded in Will County, Illinois, at a chemical production facility (estimated 5340 burrows). The wasps burrowed in the retaining berms around large chemical tanks, where all vegetation is removed for fire safety [33]. Sphecius convallis and $S$. grandis may be found in undisturbed habitats, perhaps because western regions have more open soil surface. However, the largest aggregation of $S$. convallis we observed (estimated 2093 burrows) was on a massive pile of fine, sandy mine tailings at Ruby, Arizona (Santa Cruz County)-clearly a result of human disturbance. Tall, dense vegetation impedes the ability to dig burrows and the return of female cicada killers with prey to their burrows. Presumably, dense, deep roots would make burrowing difficult as well. $S$. hogardii is reported to nest in caves [34], a natural habitat which would avoid these obstacles, as well as the potentially hydric soils of its tropical or subtropical habitats.

The number of specimens recorded for each species is roughly correlated with the extent of knowledge of it. The number of nontaxonomic, primary literature publications on S. speciosus (59 by our accounting, see [16]) is much higher than that for any of the others, $S$. grandis has the secondhighest number (7). This effect is not surprising, as investigators often choose model organisms that are abundant. $S$. hogardii has three publications, while $S$. convallis has two. This phenomenon is further reflected in Fig. (1), as $S$. speciosus is recorded extensively in areas of high human density, particularly along the east coast of the U.S.A.

Using a county-based map (Fig. 2) removes some of this effect, as a county is shown as occupied as long as one or more specimens have been recorded from it. The east coast is still well represented, but areas of the southeast and midwest also appear to hold high densities of eastern cicada killers. All bias is not removed by this method, however. Some small, densely populated eastern states have all counties represented. S. speciosus probably occurs in all counties of some of the midwestern states as well, given their relatively uniform habitat. Specimens have not been obtained from them yet, perhaps because of less intense sampling effort over a larger, less populated area. Another problem with the county-based approach is that the counties of western states are much larger than those eastern ones, resulting in a misleadingly dense distribution appearing in western states.

Our initial hypothesis, based in part on Zim and Cottam's [21] first map, was that $S$. speciosus would not be found west of the line of aridity. We also felt that $S$. speciosus was primarily a mesic species, and would require the higher rainfall characteristic of the eastern portion of the U.S.A. However, we soon found records farther west than expected. Moisture may still limit the distribution of cicada killers, but not in quite so simple a manner. In some of the western states, the records of $S$. speciosus seem to follow riverbeds. This pattern seems intuitive, as cicadas would be found in trees along these riparian corridors. However, the rivertrailing trend is difficult to distinguish from a potentially confounding effect of altitude and the fact that many roads, and thus, entomologists and human settlements, also follow river valleys in the west.

Zim and Cottam's [22] later map suggested that $S$. speciosus would be found from the east to the west coasts. We found that the western limit to its distribution was not the Pacific Ocean, but approximately along the line of $106^{\circ}$ west longitude, just east of the continental divide. High altitude, rocky soils and lack of cicadas may make it difficult for cicada killers to disperse. Hence, it seems plausible that the continental divide might form a geographic barrier to cicada killers, playing a role in their evolutionary history. Our map, in combination with recent genetic data, allows us to propose a scenario for the evolution of American Sphecius via allopatric speciation. S. grandis haplotype A appears to be the basal member of the group [35]. One would, therefore, propose its origin in the east, giving rise to the other New World species. A small number of $S$. grandis may have breached the continental divide and evolved into $S$. grandis haplotype B in the west. This new species crossed back to form $S$. speciosus in the east. Some time later, after reproductive isolation of grandis from speciosus, a few individuals of speciosus may have crossed back into the west, giving rise to $S$. convallis haplotype A. Genetic similarity between $S$. convallis haplotype B and S. speciosus, which both occur east of the continental divide, suggests that little divergence has occurred [35]. There may be high gene flow between them, owing to lack of geographic isolation. As a result of these movements, all three species are now sympatric in eight counties spread over Texas, Oklahoma, Kansas, Colorado and New Mexico. S. spectabilis appears to have split from $S$. grandis haplotype B as well [35], perhaps becoming isolated in South America. Although genetic data (and specimens in general) of S. hogardii are lacking, it is easy to conceive that $S$. speciosus isolated on a Caribbean island could readily have evolved into $S$. hogardii, which later dispersed to other islands and southern Florida. This scenario is based on few specimens, but it is parsimonious, and may provide a testable theory on the evolutionary origins and dispersal of New World cicada killer species.

In the upper Midwest of the U.S.A., the northern limit of $S$. speciosus tracks very closely the boundary between the eastern deciduous forest province and the Laurentian mixed 
forest province [36]. Hence, S. speciosus is limited on the north by the so-called "White Pine line", where the climate and habitat transition to the more Canadian type. Records become thin as this limit is approached, presumably owing to effects of cold, season length, or lack of prey. At the opposite end of its range, S. speciosus ranges throughout the southern states, into Mexico and as far south as Ecuador. Perhaps the ability to provision with a diversity of cicadas [37] contributes to the remarkably broad range of such an apparently specialized insect.

S. grandis and convallis are essentially sympatric at their northern limit in central Washington State. Cold may limit more northward dispersal, as this point is similar to the northern limit of $S$. speciosus. More significantly, these data points are near the northern edge of the Columbia River Valley, and any westward or northern progress would be blocked by the Cascade Mountains, if not by their altitude, then perhaps by the cold associated with them. Both species range through northern and central Mexico, and S. grandis, like S. speciosus, is found in southern Mexico and Central America.

Cicada killers appear to be generally limited to low altitudes. In California, records are abundant in the Salton Sea basin, Owens Valley, and Great Central Valley, but few in the Sierra Nevada, White Mountains, Coast Range, and other mountain ranges. In the Appalachian Mountains, cicada killers are largely absent from the northern and central sections, but do appear within them in the southern portions. As one proceeds south, decreasing latitude may compensate for increasing altitude. The highest altitudes in the northern hemisphere at which cicada killers were recorded were in the American southwest. This effect may also explain why $S$. speciosus encroaches on the southern portions of the Appalachian Mountains. Concentrations of cicada killers in the west also include the Columbia Basin and the Snake River Valley, where they are surrounded by mountains. Significantly, the Rocky Mountains appear to form a barrier to the eastern cicada killer. S. hogardii was found at the lowest altitudes, which is consistent with its Caribbean distribution. S. speciosus was found at somewhat higher elevations on average, which is consistent with its prevalence in the eastern US. A more surprising result was revealed in the remaining two species. S. grandis was found at the highest mean altitude, with $S$. convallis significantly lower. Although the two appear to be sympatric over much of their ranges, the altitude difference suggests one means by which the habitat may be divided, thus decreasing potential competition between them. Of the seven prey species recorded for $S$. grandis and four for $S$. convallis, only one is common between them, Tibicen parallelus [37]. These results suggest that the apparent sympatry of convallis and grandis is deceiving, as they use different altitude zones and largely prey on different species of cicadas, and that some degree of niche displacement may be occurring.

\section{ACKNOWLEDGEMENTS}

We are indebted to all the individuals who reported or sent us cicada killers and to the entomology curators of the 113 museums who lent specimens or sent label data; these institutions are listed in Appendix I of [20].

\section{REFERENCES}

[1] Spector S. Insect conservation: a time of crisis and opportunity. Am Entomol 2008; 54: 103-5.

[2] Irwin MD, Coelho JR. The distribution of the Iowan Brood of periodical cicadas (Homoptera: Cicadidae: Magicicada spp.) in Illinois. Ann Entomol Soc Am 2000; 93: 82-9.

[3] Stannard LJ. The distribution of periodical cicadas in Illinois. Ill Nat Hist Surv Biol Notes 1975; 91.

[4] Lifemapper [web site]. Lawrence, KS; University of Kansas; c2010 [updated 2010 June 15; cited 2010 June 15]. Available from http://www.lifemapper.org

[5] Stockwell DRB, Noble IR. Induction of sets of rules from animal distribution data: a robust and informative method of data analysis. Math Comput Simul 1992; 33: 385-90.

[6] Coelho JR. Spurred on to greater depths. Nat Hist 2002; 111: 20-2.

[7] Berenbaum MR. Ninety-nine gnats, nits and nibblers. USA: University of Illinois Press 1989.

[8] Teale EW. The strange lives of familiar insects. USA: Dodd, Mead \& Company 1962.

[9] Clark AH. Potent personalities: wasps and hornets. Nat Geogr Mag 1937; 72: 47-72.

[10] Champlain AB. Hunters of the treetops wherein the Cicada-killers do their stuff. Nature Mag 1929; 14: 176

[11] Riley CV. The larger digger wasp. Insect Life 1892; 4: 248-52.

[12] Dambach CA, Good E. Life history and habits of the cicada killer in Ohio. Ohio J Sci 1943; 43: 32-41.

[13] Felt EP. Notes on the cicada-killer. N Y State Mus Mem 1906; 8: 603.

[14] Tashiro H. Turfgrass insects of the United States and Canada. USA: Cornell University Press 1987.

[15] Vittum PJ, Villani MG, Tashiro H. Turfgrass insects of the United States. USA: Cornell University Press 1999.

[16] Cicada killer bibliography [web site]. Canton MO. ShowMeJoe. com; c1997-2010. Available from http://www.showmejoe.com/ thriller/ckbib.htm

[17] Krombein KA. Catalog of Hymenoptera in America north of Mexico. USA: Smithsonian Institution Press 1979; 2.

[18] Ebeling W. Urban entomology. USA: University of California Press 1975

[19] Fox WJ. Synopsis of the Stizini of Boreal America. P Acad Nat Sci Phila $1895 ; 2$ : 264-8.

[20] Holliday CW, Coelho JR, Improved key to new world species of Sphecius (Hymenoptera: Crabronidae). Ann Entomol Soc Am 2006; 99: 793-8.

[21] Zim HS, Cottam C. Insects: a guide to familiar American insects. USA: Golden Press 1951

[22] Zim HS, Cottam C. Insects: a guide to familiar American insects. USA: Golden Press 1987.

[23] Oberhauser KS, Prysby MD. Citizen science: creating a research army for conservation. Am Entomol 2008; 54: 103-5.

[24] Bohart RM. A review of the Gorytini in the neotropical region (Hymenoptera: Sphecidae: Bembicinae). Contr Entomol Int 2000; 4: 111-259.

[25] Biology of cicada killer wasps [web site]. Easton, PA; Charles W. Holliday; c2009. Available from http://sites.lafayette.edu/hollidac/

[26] The Cicada Killer Thriller Page [web site]. Canton, MO; ShowMeJoe.com; c1997-2010. Available from http:// cicadakillerthriller.showmejoe.com/

[27] Maps On Us [web site]. Dallas, TX; SuperMedia, LLC. c20092010. Available from http://www.mapsonus.com/

[28] Geographic names information system [web site]. Reston, VA; U.S. Department of the Interior c2010. Available from http://geonames.usgs.gov/pls/gnispublic/

[29] Google Earth [web site]. Mountain View, CA; Google Inc.; c2010. Available from http://earth.google.com/

[30] Eaton ER, Kaufman K. Kaufman field guide to insects of North America. USA: Houghton Mifflin 2007.

[31] Borror DJ, White RE. A field guide to the insects of America north of Mexico. USA: Houghton Mifflin 1970.

[32] Krombein KV. Kill-Devil Hills wasps. Proc Entomol Soc Wash 1953; 55: 113-35.

[33] Hastings JM, Coelho JR, Holliday CW. Mating at high population density in a colonial territorial wasp, Sphecius speciosus Drury (Hymenoptera : Crabronidae). J Kans Entomol Soc 2008; 81: 3018. 
[34] Genaro JA, Juarrero de Varona C. Comportamiento de Sphecius hogardii durante la nidification (Hymenoptera : Sphecidae). Caribb J Sci 1998; 34: 323-4.

[35] Hastings JM, Schultheis PJ, Whitson MK, Holliday CW, Coelho JR, Mendell AM. DNA Barcoding of new world cicada killers (Hymenoptera: Crabronidae). Zoo Taxa 2008; 1713: 27-8.
[36] Regional landscape ecosystems of Michigan, Minnesota, and Wisconsin [web site]. Northern prairie wildlife research center, Jamestown, North Dakota; c2006. Available from http://www. npwrc.usgs.gov/resource/habitat/rlandscp/intro.htm

[37] Holliday CW, Hastings JM, Coelho JR. Cicada prey of new world cicada killers, Sphecius spp. (Dahlbom 1843) (Hymenoptera: Crabronidae). Entomol News 2009; 120: 1-17.

Received: April 10, 2010

Revised: March 29, 2011

Accepted: May 04, 2011

(C) Coelho et al.; Licensee Bentham Open.

This is an open access article licensed under the terms of the Creative Commons Attribution Non-Commercial License (http://creativecommons.org/licenses/by$\mathrm{nc} / 3.0 /$ ), which permits unrestricted, non-commercial use, distribution and reproduction in any medium, provided the work is properly cited. 